\title{
Electrospray array heat transfer
}

\author{
M.J. Gibbons ${ }^{\mathrm{a}, *}$, A.J. Robinson ${ }^{\mathrm{a}}$ \\ ${ }^{a}$ Department of Mechanical, Manufacturing and Biomedical Engineering, Trinity College Dublin, the University of Dublin, Dublin 2, \\ Ireland.
}

\begin{abstract}
Multiple source electrospraying enables higher droplet mass flux and greater cooling coverage area in comparison with its single source counterpart. The local convective heat flux to a multiple source electrospray array operating in the evaporative cooling regime has been investigated using thin foil thermography. The designed array had a packing density of $115 N_{n} \mathrm{~cm}^{-2}$ and was operated in the cone-jet regime of spraying with ethanol as the working fluid. The electrospray array heat transfer performance is explored for varied flow rate $\left(Q=2-4 \mu \mathrm{L} \mathrm{min}{ }^{-1} N_{n}^{-1}\right)$ and electric field $\left(E_{d}=4-8 \mathrm{kV} \mathrm{cm}^{-1}\right)$. Cooling performance was shown to be dependent on both parameters. An $89 \%$ and $64 \%$ increase in the peak and average heat flux respectively was noted for the increasing driving electric fields case. This was due to increasing droplet mass flux, resulting in increasing contact line length density on the heated substrate, from narrowing of the spray plume, reduced residence time and droplet evaporation en-route to the target surface. This narrowing spray plume, at higher driving electric fields, also resulted in a more defined radial convective heat flux profile. The performance of the array was compared with that of a single source under similar experimental conditions. The array achieved more uniform cooling over a larger area than its single source counterpart. Comparing both devices for similar total working fluid flow rate highlight that the array delays the onset of pool cooling. This enables higher total working fluid flow rates in the evaporative cooling regime and subsequently higher convected thermal energy.
\end{abstract}

Keywords: Electrospray, Heat transfer, Electronic cooling, Spray cooling, Electric field

\section{Introduction}

There is a growing expectation on small form factor electronics to be more compact while also increasing performance. This trend has resulted in increasing generated heat flux density due to the increasing transistor density, chip resistance, capacitance, and subsequent charge leakage [1]. This progression has driven conventional cooling technologies to a thermal management threshold, where they are unable to remove the generated thermal load. Future high speed processor are predicted to achieve heat fluxes of $500 \mathrm{~W} \mathrm{~cm}^{-2}$ ranging up to $1000 \mathrm{~W} \mathrm{~cm}^{-2}$ at hot spots [2-4]. Forced air convection can achieve a heat flux removal of $150 \mathrm{~W} \mathrm{~cm}^{-2}$ [5], while $120 \mathrm{~W} \mathrm{~cm}^{-2}$ can be obtained through pool boiling of water [6]. In order to maintain chip performance, life cycle and avoid component failure it is imperative to keep on-chip surface temperatures below $85^{\circ} \mathrm{C}[7-9]$. Clearly a step change in thermal management technology is required to overcome the thermal load generated from the next generation of microelectronics. An emerging solution to this problem is cone-jet electrospray cooling (EC).

Electrospraying is a method of fluid atomisation by electrostatic means (see Fig. 1). It can be divided into a

\footnotetext{
* Corresponding author

Email address: Michael.Gibbons@tcd.ie (M.J. Gibbons)
}

number of different operating regimes, some of which were initially identified by Zeleny $[10,11]$ and later more comprehensively classified by Cloupeau and Prunet-Foch [12]. A widely applied functioning mode is the "cone-jet" characterised by Cloupeau and Prunet-Foch [13]. Cone-jet electrospray electrode design can be divided into two configurations: two electrodes (source-target), and three electrodes (source-extractor-target), these are shown in Fig. 2. The three electrode design utilises an intermediate extractor electrode between the source and target electrodes.

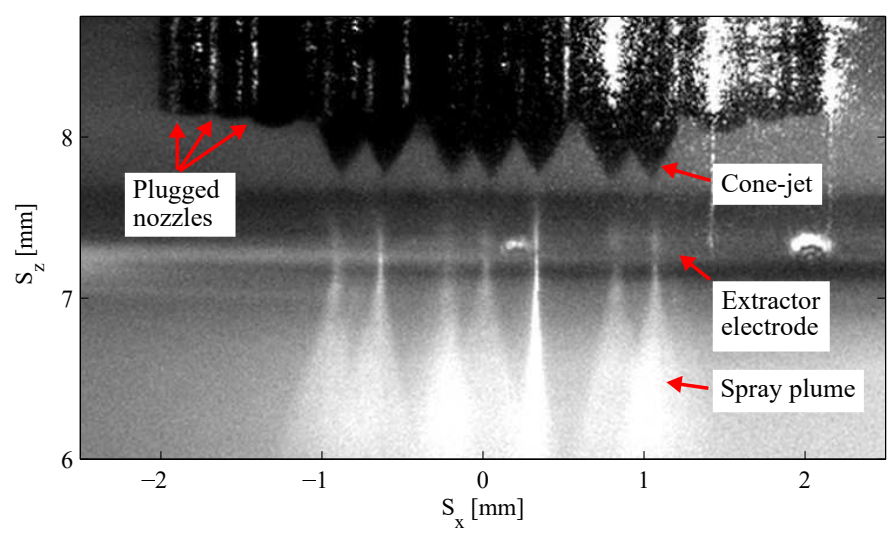

Figure 1: Electrospray array. $D_{i}=200 \mu \mathrm{m}, D_{o}=400 \mu \mathrm{m}, H_{1}=$ $0.5 \mathrm{~mm}, H_{2}=7.5 \mathrm{~mm}, Q=3 \mu \mathrm{Lmin}^{-1} N_{n}^{-1}, V_{n}=7.1 \mathrm{kV}, V_{\text {ex }}=$ $6 \mathrm{kV}, E_{d}=8 \mathrm{kV} \mathrm{cm}^{-1}$, and $q_{g e n}^{\prime \prime}=1,395 \mathrm{~W} \mathrm{~m}^{-2}$. 


\begin{tabular}{|c|c|c|c|}
\hline \multicolumn{4}{|c|}{ Nomenclature } \\
\hline$C_{p}$ & specific heat capacity $\left[\mathrm{J} \mathrm{kg}^{-1} \mathrm{~K}^{-1}\right]$ & $\infty$ & bulk or infinity \\
\hline$D$ & nozzle diameter $[\mu \mathrm{m}]$ & $a g$ & air gap \\
\hline$H_{1}$ & source-extractor separation height $[\mathrm{mm}]$ & cap & capacitive or storage \\
\hline $\mathrm{H}_{2}$ & extractor-target separation height $[\mathrm{mm}]$ & $c h$ & nozzle channel \\
\hline I & current $[\mathrm{A}]$ & cond & conduction \\
\hline$j_{m}$ & mass flux $\left[\mathrm{kg} \mathrm{m}^{-2} \mathrm{~s}^{-1}\right]$ & $d$ & droplet \\
\hline$k$ & thermal conductivity $\left.\left[\mathrm{W} \mathrm{m}^{-1} \mathrm{~K}^{-1}\right]\right]$ & $e x$ & extractor electrode \\
\hline$L$ & length $[\mathrm{mm}]$ & $f$ & foil \\
\hline$N_{n}$ & number of nozzles [-]] & gen & generated \\
\hline$Q$ & working fluid flow rate $\left[\mu \mathrm{L} \min ^{-1}\right]$ & $i$ & inner \\
\hline$q$ & heat transfer rate $[\mathrm{W}]$ & $i$ & outer \\
\hline$q^{\prime \prime}$ & heat flux $\left[\mathrm{W} \mathrm{m}^{-2}\right]$ & $j$ & jet \\
\hline$r$ & radial distance from nozzle centre $[\mathrm{mm}]$ & $l c$ & lateral conduction \\
\hline$S$ & coordinate $[\mathrm{mm}]$ & $n$ & source nozzle \\
\hline$s$ & nozzle spacing $[\mathrm{mm}]$ & $p$ & paint \\
\hline$T$ & temperature $[\mathrm{K}]$ & $\mathrm{rad}$ & radiation \\
\hline & voltage $[\mathrm{V}]$ & $s$ & heated substrate \\
\hline & energy $[\mathrm{J}]$ & $w f$ & working fluid \\
\hline \multirow{2}{*}{\multicolumn{4}{|c|}{$\begin{array}{l}\text { Dimensionless Numbers } \\
B i \quad B i=h L / k[-]\end{array}$}} \\
\hline & & & \\
\hline \multicolumn{2}{|c|}{ Greek Symbols } & \multicolumn{2}{|l|}{ Acronyms } \\
\hline & thickness $[\mu \mathrm{m}]$ & CLD & contact line length density \\
\hline$\gamma$ & surface tension $\left.\left[\mathrm{N} \mathrm{m}^{-1}\right]\right]$ & DC & direct current \\
\hline & density $\left[\mathrm{kg} \mathrm{m}^{-3}\right]$ & EC & electrospray cooling \\
\hline & Stefan-Boltzmann constant $\left[\mathrm{W} \mathrm{m}^{-2} \mathrm{~K}^{-4}\right]$ & IR & infrared \\
\hline$\varepsilon$ & emissivity [-] & PEEK & $\begin{array}{l}\text { natural convection } \\
\text { polyether ether ketone }\end{array}$ \\
\hline$S u b$ & & PU & percentage uncertainty \\
\hline
\end{tabular}

The extractor electrode typically consists of a thin plate $\left(\delta_{e x} \sim 200 \mu \mathrm{m}\right)$ with holes concentric to that of the source nozzles to allow the generated spray to pass through [1416]. Both designs achieve cone-jet electrospraying in a similar manner but the three electrode configuration increases complexity and is normally applied in multiple source applications [15, 17-20]. A comprehensive description of the electrospray cooling process has been discussed previously by Gibbons and Robinson [21]. An illustration of the three electrode electrospraying process and the relevant electrospray array length scales are shown in Fig. 3 and Fig. 4 respectively. In the three electrode configuration (Fig. 2b), a suitable working fluid is supplied to the tip of a source nozzle which is maintained at an electrical potential above that of an adjacent extractor electrode. This potential difference creates an electric field, and when a sufficient electric field is established, the meniscus at the tip of the source nozzle deforms into the shape of a liquid cone (see Fig. 1), often referred to as a Taylor cone [22]. This conical shape is as a result of the balance of surface tension, viscous, hydrostatic, gravitational, and electrostatic forces. At the apex of this cone a thin permanent jet is formed. The jet passing through the extractor electrode undergoes Rayleigh instability and breaks up into quasi-monodisperse micron-sized charged droplets. The generated droplets are then propelled towards the target ground electrode by the electric field between the extractor and target surface. Often two families of droplets are produced; primary and satellite. Primary droplets make up $\approx 97 \%$ of the flow and $\approx 86 \%$ of the current [23]. Coulombic repulsion of the charged droplets enables spray plume dispersion (Fig. 1) and droplet segregation, with primary droplets located in the core of the plume and satellite droplets orientated on the periphery of the spray due to their greater initial charge and reduced inertia in comparison with primary droplets [23]. Coulomb attraction between the charged droplets and grounded target surface negates droplet rebound and increases droplet spreading during impact [24] resulting in a more effective heat transfer process [16, 25].

The additional intermediate electrode enables localisation of the electric field at the source electrode and shields the cone-jet from the highly charged generated spray cloud [15]. The extractor design enables a more 


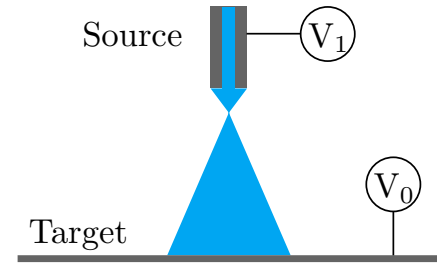

(a)

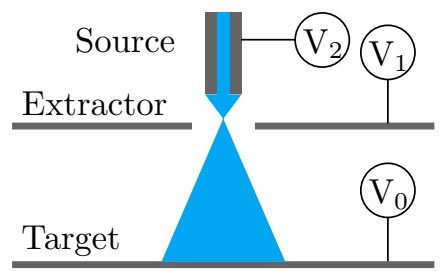

(b)
Figure 2: Electrospray electrode configuration. (a) Two electrode design, (b) three electrode design.

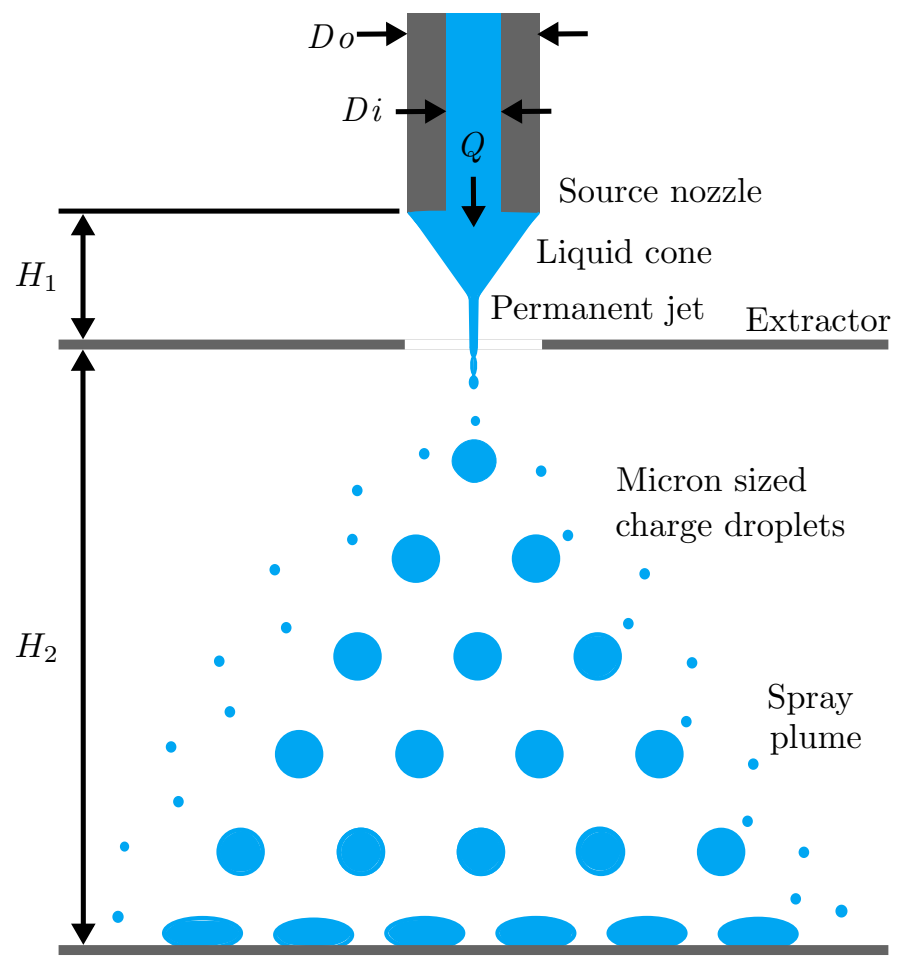

Figure 3: Three electrode electrospraying schematic.

stable spray process and a degree of plume dispersion control [26]. Two separate electric fields exist in this design, the jet forming electric field $E_{j}$ between the source and extractor and the driving electric field $E_{d}$ between the extractor and target electrodes. Once a suitable potential drop is established between the source and extractor it is possible to vary the driving electric field to alter plume dynamics. Yang et al. [26] showed that a higher $E_{d}$ resulted in a more concentrated plume. This is due to the increased droplet velocity in the spray direction arising from the increasing electric field. This results in a shorter droplet residence time allowing less time for plume dispersion. Deng and Gomez [27] defined a minimum $E_{d}$ that is required to prevent "satellite trapping". This is flow reversal of satellite droplets back to the extractor electrode. This can result in flooding between the source and extractor electrode which is detrimental to spraying. They showed that varying $E_{d}$ has no impact on the produced droplet size. The greatest advantage of the three electrode configuration is in the realisation of high density electrospray arrays operating the

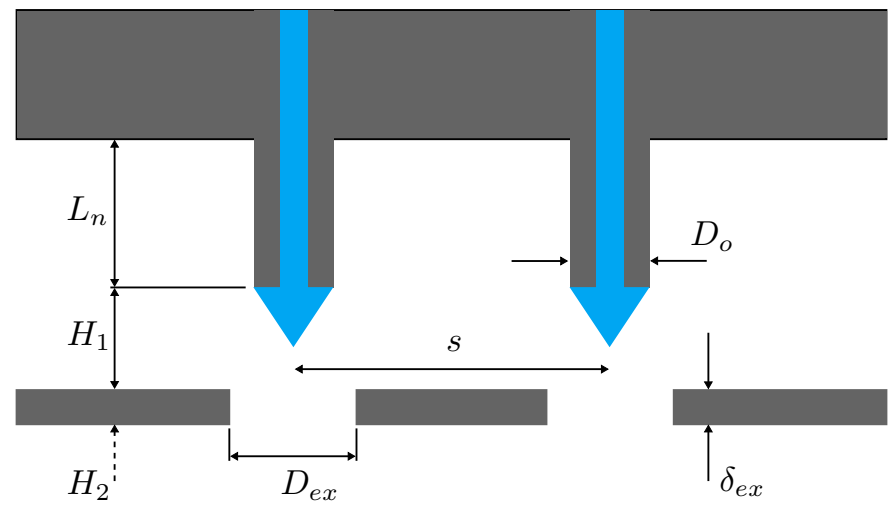

Figure 4: Three electrode electrospray array length scales.

cone-jet regime of spraying.

Electrospraying has applications in a wide variety of research areas such as: colloidal propulsion [28-31], mass spectrometry [32], material production and coating [3338], bio-sciences [33, 39-42], and microcombustion [43-46]. Electrospraying is an attractive proposition for cooling applications given its generation of monodisperse micron sized charged droplets [23, 47-49], avoidance of droplet coalescence and self spray dispersion due to Coulomb repulsions [23], negation of droplet impact rebound and increased droplet spreading upon impact due to Coulomb attraction [24], and minimal energy and space requirements [6, 17]. These properties can lead to a more effective heat transfer processes in comparison with other conventional spray systems $[17,25]$. This makes EC technology particularly attractive for space applications, given the inherent size and weight restrictions coupled with the absence of buoyancy forces for natural convection cooling.

Spray cooling is the parent field of electrospray cooling incorporating atomisation of a liquid by means other than by electrostatic forces. Spray cooling is an attractive proposition as it is one of the most efficient heat flux removal mechanisms per unit flow [50, 51]. Spray cooling electronic devices can reduce power consumption by $35 \%$ in comparison to the more conventional air cooling systems [52]. The state of the art of spray cooling has recently been reviewed by Liang and Mudawar [53, 54]. Prior research in the field of electrospray cooling is very limited. Notably the work of Gibbons and Robinson [25] and Deng and Gomez [17, 24], has shown that EC is a promising thermal management solution.

Feng and Bryan [55] were the first to investigate two phase electrospray cooling (EC). Their research studied the average heat transfer enhancement of different nozzle arrays in an enclosed chamber under various spraying regimes with ethanol. They operated primarily outside the cone-jet mode. Their work showed that an optimum average heat transfer enhancement of 1.7 times over the no applied electric field case. This condition corresponded to a single nozzle, inner diameter $D_{i}=0.25 \mathrm{~mm}$, at their smallest nozzle-target separation height $H=5 \mathrm{~mm}$, for a 
flow rate of $Q=3000 \mu \mathrm{L} \mathrm{min}{ }^{-1}$. This fluid was deposited onto $50 \mathrm{~mm}^{2}$ surface with a heat flux of $10 \mathrm{~W} \mathrm{~cm}^{-2}$ and a fixed liquid layer appears to have been maintained on the heated substrate. The spraying regime was unspecified but an applied voltage of $7 \mathrm{kV}$ was noted. Due to the enclosed nature of their test section, a higher wall heat flux resulted in greater vapour momentum away from the surface minimizing the effect of some spraying regimes. The multiple source array enabled increased heat transfer enhancement at higher flow rates and lower heat fluxes.

Wang and Mamishev [56] investigated the average heat transfer of enclosed electrospraying chambers for three different geometry types in the multi-jet regime. They achieved a maximum average heat transfer enhancement of 1.87 fold over natural convection (NC) for their 8 source, $5 \mathrm{~mm}$ pitch array at the lowest wall heat flux of $4,384 \mathrm{~W} \mathrm{~m}^{-2}$. This case corresponded to a $H=7.5 \mathrm{~mm}, D_{i}=0.210 \mathrm{~mm}$ and $Q=133.33 \mu \mathrm{L} \mathrm{min}^{-1}$. Like Feng and Bryan, they noticed an increasing enhancement for decreasing wall heat fluxes. They stipulated that increasing the number of sources and their spacing does not improve the steady state heat transfer. However it does increase the transient average heat transfer performance. Wang and Mamishev [57] later developed a set of correlations for the average heat transfer enhancement ratio and Nusselt number for an electrospray operated in the multi-jet regime. Their model for the heat transfer enhancement over natural convection showed $83 \%$ agreement with their experimental data, within a $\pm 10 \%$ deviation. Their models performed well at lower flow rates with erroneous results appearing at higher flow rates. Wang and Mamishev stipulated that this was due to excessive coolant deposition on the target surface.

Deng and Gomez [17] constructed and tested 19 and 37 sourced multiplexed electrospray arrays with a source density of 253 sources $\mathrm{cm}^{-2}$. They operated in the cone-jet regime utilising an extractor design. An optimal average heat flux removal of $96 \mathrm{~W} \mathrm{~cm}^{-2}$ was noted for the highest flow rate $\left(1666.67 \mu \mathrm{L} \mathrm{min}{ }^{-1}\right)$. By reducing the generated droplet size through increasing the electrical conductivity of the working fluid, they achieved an increase in average heat flux removal of $25 \%$ compared to the undoped ethanol case. From these results Deng and Gomez [17] suggested that producing the smallest droplets at the highest rate would optimise both spray efficiency and average heat flux removed. This can be achieved by optimising the packing of source nozzles to achieve small droplets for larger total flow rates.

Gibbons and Robinson [25] parametrically investigated the local heat transfer to an impinging single source electrospray operating in the cone-jet regime. This was done using thin foil IR thermography and ethanol as the working fluid. Two distinct cooling regimes were observed: evaporative and pooling cooling. These regimes were dependent on the heated substrate properties, applied generated power, liquid mass flux impinging on the surface, ambient surroundings, and the latent heat of evaporation of the cooling fluid. The evaporative regime consisted of

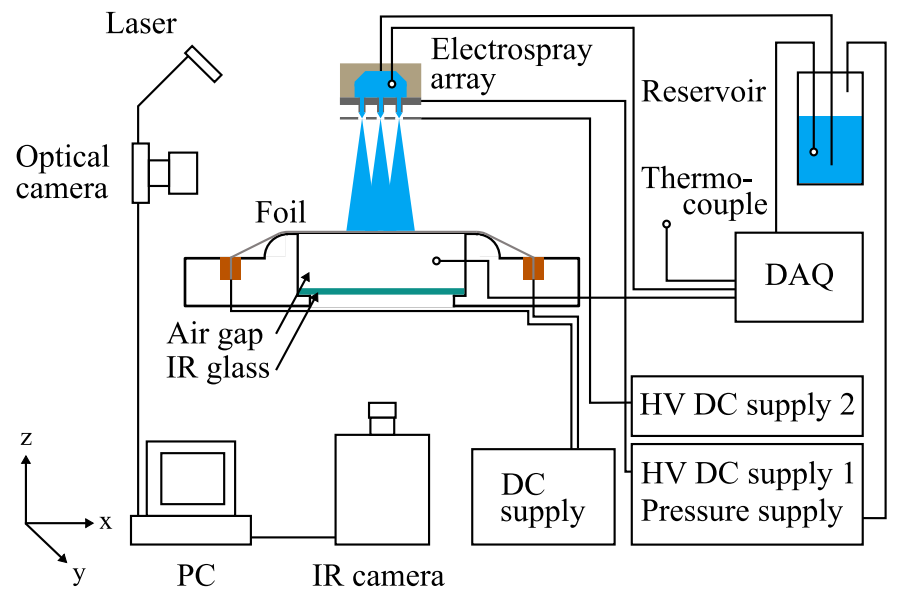

Figure 5: Schematic diagram of experimental set-up.

individual droplet impingement and evaporation on the heated substrate forming multiple contact lines. Whereas, pool cooling was defined by a coalescence of the impacted droplets on the heated substrate to form a quasi-steady macro-sized liquid film. Maximum heat transfer was noted in the evaporative regime prior to cooling regime transition (CTP) at the smallest explored separation heights. A peak local heat transfer of 18.7 times over natural convection was shown in the evaporative mode at $H=2.5 \mathrm{~mm}$, $Q=4 \mu \mathrm{L} \mathrm{min}^{-1}, D_{i}=0.330 \mathrm{~mm}, D_{o}=0.629 \mathrm{~mm}$, and $V_{n}=2.03 \mathrm{kV}$. The pool cooling regime was largely defined by the evaporation in region around the singular contact line of the macro-sized formed droplet.

This research endeavors to be the first to investigate the local heat transfer distribution to a multiple source electrospray. This was achieved using an electrically heated thin foil and thermal imaging system in order to fully investigate and characterise the local heat transfer features of the electrospray under varied working fluid flow rate and applied electric field.

\section{Experimental Apparatus and Data Reduction}

The experimental apparatus consists of three primary components; the heat transfer section, the electrospray generation and imaging system. These are illustrated in the rig schematic in Fig. 5.

\subsection{Heat transfer section}

The thermal exchange section (shown in Fig. 6) consists of a $25 \mu \mathrm{m}$ thick, $140 \times 80 \mathrm{~mm}^{2} 316$ stainless steel foil (Goodfellow, Fe/Cr18/Ni10/Mo3, P/N: 505-400-04). The foil is clamped between two copper busbars (Fig. 6c), with both busbars electrically connected to a DC power supply (Lambda GENESYS 6-200, P/N: GEN 6-200). The copper busbars are mounted to a polyether ether ketone (PEEK, Ketron 1000 PEEK) housing. This PEEK housing is shown in Fig. 6a. A tensioning system is employed 


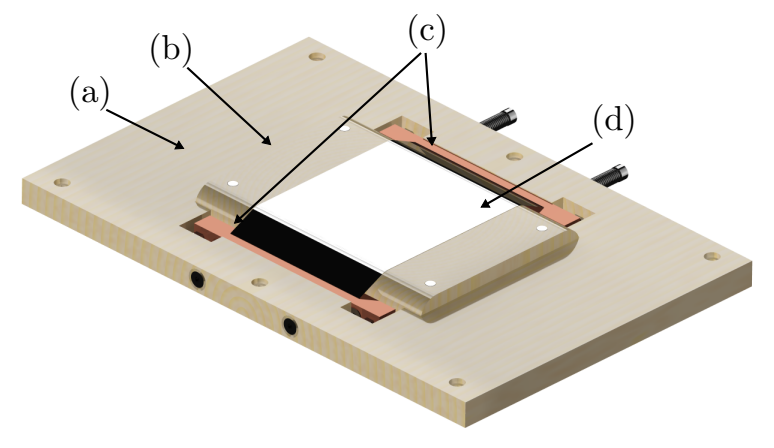

Figure 6: Thermal exchange section. (a) PEEK housing, (b) central PEEK piece, (c) copper busbars, and (d) stainless steel foil.

in order to counteract foil warping at higher foil temperature gradients. One set of busbars are rigidly fixed to the PEEK housing while the other is spring loaded. The $25 \mu \mathrm{m}$ foil is stretched across a $140 \times 100 \times 13 \mathrm{~mm}^{3}$ central PEEK piece shown in Fig. 6b. It is noted that the resistance to lateral heat flow using block heaters can be significantly less which influences the conjugate heat transfer behaviour in such a way that the block heater technique should show increased thermal performance compared to the thin foil technique [58]. However, the thin foil technique allows for the local distribution of the convective heat flux to be estimated, which is not possible with the traditional heated meter bar technique where a block heater is used.

The central PEEK piece serves to house a $70 \times 70 \times 2$ $\mathrm{mm}^{3}$ infrared (IR) transparent calcium fluoride $\left(\mathrm{CaF}_{2}\right)$ window. The top of this IR window is positioned $7 \mathrm{~mm}$ below the underside of the foil. This configuration establishes a $71 \times 71 \times 7 \mathrm{~mm}^{3}$ air cavity, minimising heat lost from the underside of the foil. A $1.6 \mathrm{~mm}$ exposed T-type thermocouple is used to measure the air temperature at the midpoint of the air gap cavity. The underside of the foil is exposed for direct temperature measurement by an infrared camera. It is coated with a thin layer of matt black paint of known emissivity to facilitate accurate temperature measurement.

Table 1: Foil and paint properties.

\begin{tabular}{lrl}
\hline Foil thickness, $\delta_{f}$ & 25 & $\mu \mathrm{m}$ \\
Density, $\rho_{f}$ & 7960 & $\mathrm{~kg} \mathrm{~m}^{-3}$ \\
Thermal conductivity, $k_{f}$ & 16.3 & $\mathrm{~W} \mathrm{~m}^{-1} \mathrm{~K}^{-1}$ \\
Specific heat, $\mathrm{C}_{p, f}$ & 502 & $\mathrm{~J} \mathrm{~kg}^{-1} \mathrm{~K}^{-1}$ \\
${\text { Surface Roughness, } R a_{f}}_{\mathrm{CaF}_{2} \text { Emissivity, } \varepsilon_{C a F_{2}}}^{59.52}$ & $\mathrm{~nm}$ \\
${\text { Paint layer thickness, } \delta_{p}}$ & 0.2 & - \\
Density, $\rho_{p}$ & 10.52 & $\mu \mathrm{m}$ \\
Thermal conductivity, $k_{p}$ & 1261 & $\mathrm{~kg} \mathrm{~m}^{-3}$ \\
Specific heat, C & 0.095 & $\mathrm{~W} \mathrm{~m}_{p, p}$ \\
Paint Emissivity, $\varepsilon_{p}$ & 2835 & $\mathrm{~J} \mathrm{~kg}^{-1} \mathrm{~K}^{-1}$ \\
\hline
\end{tabular}

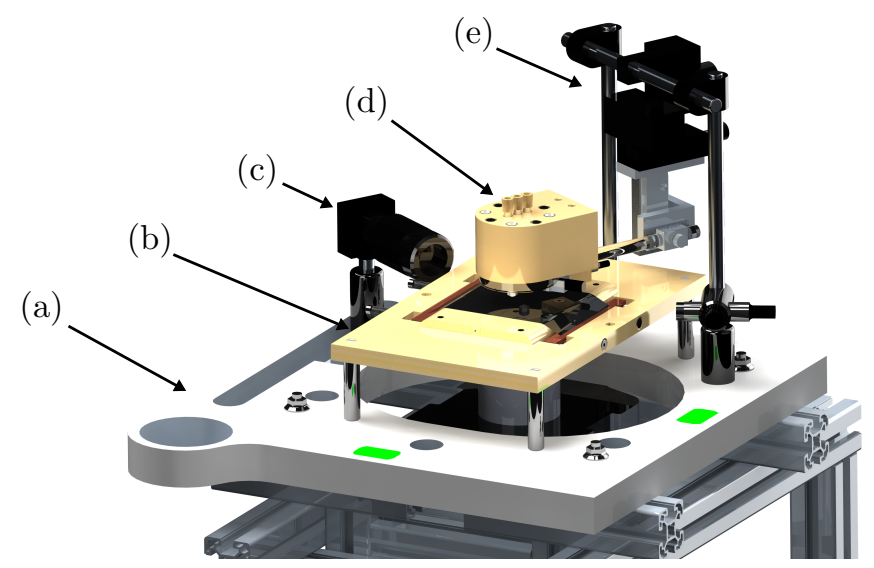

Figure 7: Electrospray baseplate configuration. (a) Acetal baseplate, (b) thermal exchange section, (c) optical camera, (d) electrospray array, and (e) XYZ micropositioner.

\subsubsection{Material Properties}

The foil and paint properties are outlined in Table 1. The paint thickness was determined using a Dektak $6 \mathrm{M}$ programmable surface profiler. The foil properties were defined using the supplier data sheet, while the paint layer was determined from data tabulated by Donoghue [59] and Raghu and Philip [60]. The surface roughness of the steel foil was determined using a MicroXAM White light Interferometric Surface Profiler.

\subsection{Electrospray Generation System}

The thermal exchange section is mounted on an acetal baseplate (Fig. 7a), $400 \times 320 \times 30 \mathrm{~mm}^{3}$, which is supported on a $40 \times 40 \mathrm{~mm}^{2}$ aluminium profile frame. The working fluid was ethanol (Fisher Scientific, $\mathrm{C}_{2} \mathrm{H}_{5} \mathrm{OH}$, density $790 \mathrm{~kg} \mathrm{~m}^{-3}$, boiling point: $78.37^{\circ} \mathrm{C}$, Assay (GC): $>99.8 \%$, Water $<0.3 \%$, and $\mathrm{P} / \mathrm{N}: \mathrm{E} / 0665 \mathrm{DF} / 17)$. A variable pressure head was supplied to the working fluid reservoir (Fig. 5) from a Spraybase controller (Avectas, DC power: $0-30 \mathrm{kV}$, pressure head: $0-5 \mathrm{bar}$, and $\mathrm{P} / \mathrm{N}$ : CAT000040)

. The controller regulates the output pressure between 0 5 bar. This output can be set to a precision of 1 mbar. The applied pressure drives the ethanol flow through the fluidic circuit. A Sensirion liquid flow sensor (P/N: SLI0430) was used to record the working fluid flow rate. The source electrode potential was supplied by $0-30 \mathrm{kV}$ DC power supply and the extractor electrode by a $0-20 \mathrm{kV}$ DC power supply (Avectas, DC power: $0-20 \mathrm{kV}$ and $\mathrm{P} / \mathrm{N}$ : CAT000005). The source and extractor electrodes were electrically insulated from each other using nylon screws (Fig. 8a) and M4 PEEK spacers (Fig. 8f).

An electrospray array was developed (see Fig. 7d) and the relevant design length scales are shown in Table 2. An exploded view of the array assembly is shown in Fig. 8 and a section view is presented in Fig. 9. The array consisted of three key components: PEEK reservoir, source electrode, and extractor electrode. The source electrode was constructed by integrating 19 stainless steel AISI 304 
Table 2: Electrospray array design summary.

$\begin{array}{lrl}\text { Configuration } & \text { Triangular } & \\ \text { Number of sources, } N_{n} & 7 & \\ \text { Nozzle spacing, } s & 1 & \mathrm{~mm} \\ \text { Nozzle density, } \rho_{N_{n}} & 115 & N_{n} \mathrm{~cm}^{-2} \\ \text { Nozzle inner diameter, } D_{i} & 200 & \mu \mathrm{m} \\ \text { Nozzle outer diameter, } D_{o} & 400 & \mu \mathrm{m} \\ \text { Nozzle height, } L_{n} & 570 & \mu \mathrm{m} \\ \text { Nozzle channel length, } L_{c h} & 34 & \mathrm{~mm} \\ \text { Source-Extractor separation, } & 500 & \mu \mathrm{m} \\ H_{1} & 600 & \mu \mathrm{m} \\ \text { Extractor hole diameter, } D_{e x} & 200 & \mu \mathrm{m} \\ \text { Extractor thickness, } \delta_{e x} & & \end{array}$

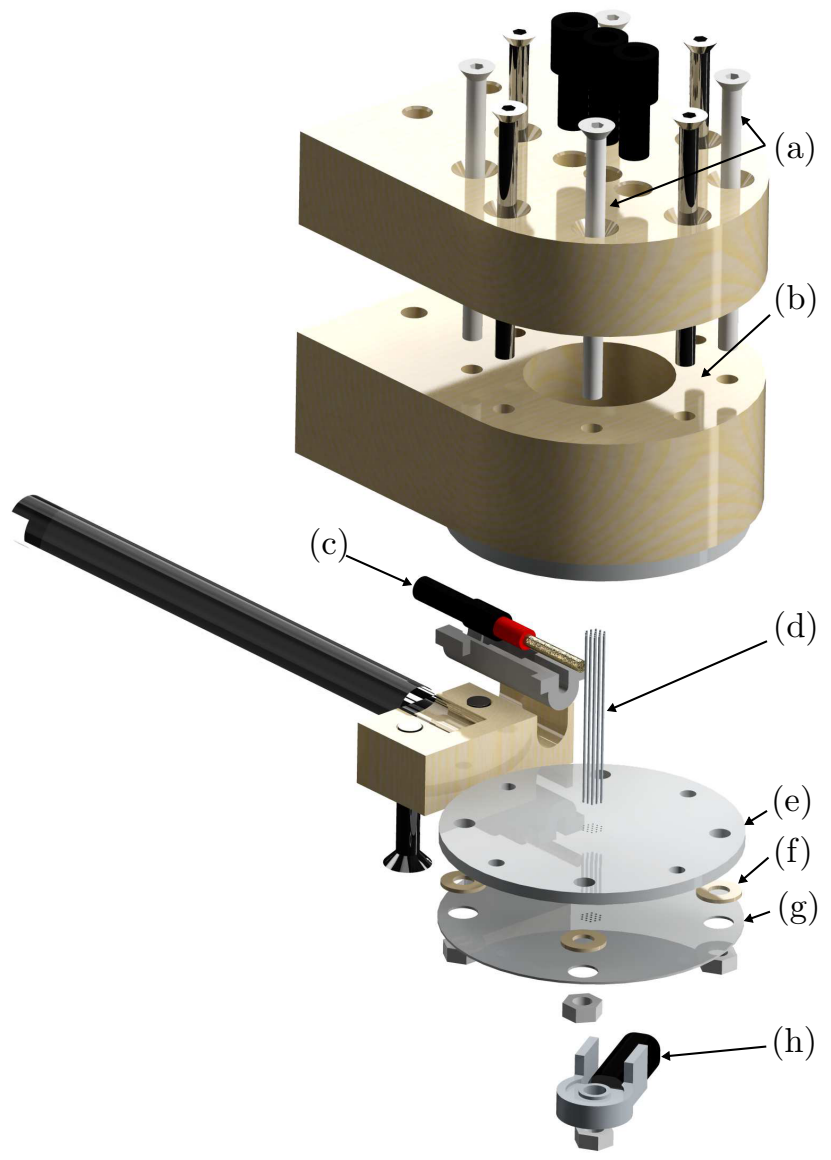

Figure 8: Electrospray array exploded view. (a) Nylon screws, (b) PEEK reservoir, (c) source electrode connection, (c) $19 \times$ source nozzles, (d) source electrode, (e) PEEK spacers, (f) extractor electrode, and $(\mathrm{g})$ extractor electrode connection.

capillaries (Fig. 8d) into a $3 \mathrm{~mm}$ thick stainless steel plate (Fig. 8e). The capillaries were fixed in place first using electrically conductive silver epoxy and later using Loctite 9497 epoxy. The source electrode was mounted and sealed against the PEEK reservoir during testing (Fig. 9h).

The PEEK reservoir (Fig. 9d) was filled with 250$500 \mu \mathrm{m}$ diameter glass beads (Retsch, P/N: 22.222.0002) to minimise dead volume and increase flow resistance. Dur-

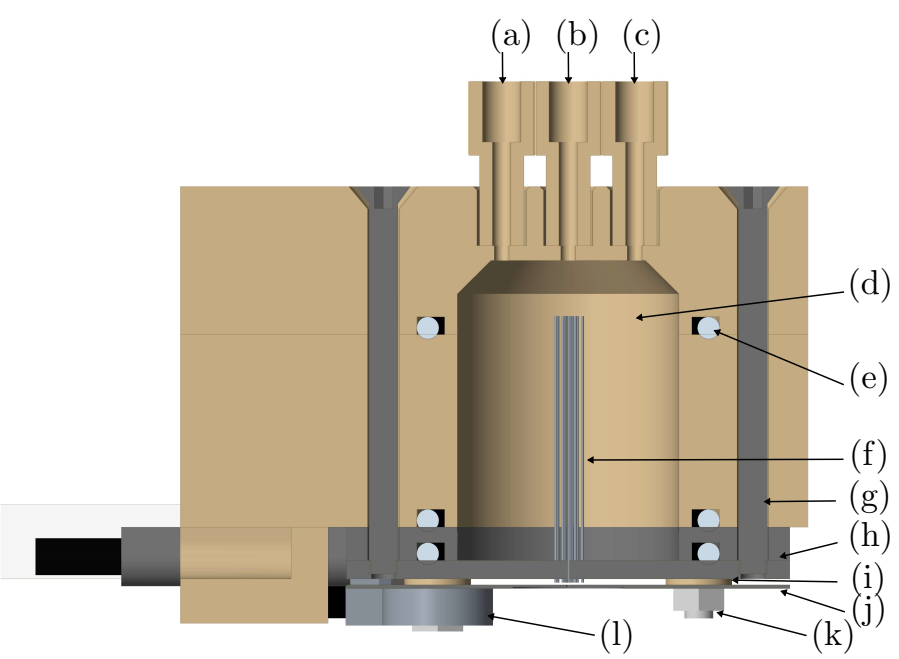

Figure 9: Electrospray array section view. (a) Bleed valve, (b) working fluid input, (c) thermocouple measurement access, (d) working fluid reservoir packed with glass beads, (e) o-ring seal, (f) $19 \times$ source nozzles, (g) stainless steel screw, (h) source electrode, (i) PEEK spacers, (j) extractor electrode, (k) nylon screw and nut, and (l) extractor electrode connection.

ing testing the reservoir is completely filled with ethanol to remove all air from the system. Edge effect were eliminated by plugging the outside ring of 12 source nozzles and by applying an appropriate source flow resistance. This was done to ensure a uniform flow rate across all source nozzles in the array. The flow resistance of the designed array was compared with an array designed by Deng et al. [14, 18]. Deng et al. reported consistent droplet size across all sources during testing. The array used in the present study has a flow resistance 4.9 times greater than that employed by Deng et al.

\subsection{Imaging system}

The imaging system consisted of two parts; a Chameleon CMLN-1352M optical camera and a FLIR SC6000 thermal imaging camera. Both cameras are controlled by a dedicated computer. The optical camera is mounted to the acetal baseplace as shown in Fig. 7a. It was used to focus on the source nozzle and define cone-jet spraying during testing.

The FLIR SC6000 high resolution, high frame rate IR camera was used to capture the thermal footprint of the electrospray plume. The camera is mounted to the aluminium profile, directly below the thermal exchange surface. The IR camera is fitted with a $25 \mathrm{~mm}$ focal length lens. The frame rate and capturing period is controlled via an external pulse generated by a National Instruments (NI) 9401 Data Acquisition Module (DAQ) in LabVIEW. The thermal camera is set to record an image that is $400 \times 400$ pixels with each pixel corresponding to a width of $157 \mu \mathrm{m}$.

\subsection{Experimental parameters}

All tests were conducted in the cone-jet regime of spraying. The applied voltages and flow rate ranged between 
Table 3: Recording frequency of data acquisition.

\begin{tabular}{lrc}
\hline IR camera & 200 & $\mathrm{~Hz}$ \\
Optical camera & 15 & $\mathrm{~Hz}$ \\
Foil voltage drop, $V_{s}$ & 50 & $\mathrm{~Hz}$ \\
Foil Current, $I_{s}$ & 50 & $\mathrm{~Hz}$ \\
Flow rate, $Q$ & 2 & $\mathrm{~Hz}$ \\
Air gap temperature, $T_{a g}$ & 1.8 & $\mathrm{~Hz}$ \\
Ambient temperature, $T_{\infty}$ & 1.8 & $\mathrm{~Hz}$ \\
Working fluid temperature, $T_{w f}$ & 1.8 & $\mathrm{~Hz}$ \\
\hline
\end{tabular}

2-10 $\mathrm{kV}$ and $2-4 \mu \mathrm{Lmin}{ }^{-1} N_{n}^{-1}$ respectively during experimentation. The extractor electrode-heated substrate separation height $\mathrm{H}_{2}$ was set at $7.5 \mathrm{~mm}$. Experiments were conducted at atmospheric pressure and room temperature after steady state conditions were reached. The heated substrate temperature was assumed to be uniform across its thickness at a constant heat flux generation of 1,395 $\mathrm{W} \mathrm{m}^{-2}$ was maintained for all test points. This corresponded to a surface temperature of $\sim 90^{\circ} \mathrm{C}$ in the absence of EC.

\subsection{Experimental procedure}

Prior to each test, the separation height, flow rate and surface heat flux are set. The working fluid coolant is primed to the source nozzle tips. The potential drop between the source and extractor electrode is adjusted to the onset voltage of the cone-jet regime. Once cone-jet spraying is established, the spray is allowed to reach steady state. Data acquisition is triggered using custom code developed in LabVIEW. Once the program is started it triggers the thermal imaging camera and optical camera, while simultaneously acquiring thermocouple, flow rate, foil voltage drop and circuit current readings. Data is acquired over a 10 second period. The recording rates of all relevant parameters are outlined in Table 3.

\subsection{Data analysis and processing}

The captured thermal images are processed using MATLAB. Processing of data can be divided into three phases; image conversion, heat transfer analysis and averaging.

\subsubsection{Image conversion}

For each test point the acquired data is imported into MATLAB. Each frame is extracted and the bad pixel, gain, offset and counts to temperature conversion are applied. This results in $2000400 \times 400$ thermal images stored in a 3D array.

\subsubsection{Heat transfer analysis}

In order to compute the thermal energy convected to the electrospray array, various fluid, foil and paint properties (see Table 1) are input along with the averaged values for the relevant acquired data (thermocouple, flow rate, foil voltage drop and circuit current). In order to evaluate the thermal energy convected to EC, an element by element based energy balance is applied to each pixel of the recorded thermal image. The energy balance can be defined as [61]:

$$
\dot{W}_{\text {in }}+\dot{W}_{\text {gen }}-\dot{W}_{\text {out }}=\dot{W}_{\text {cap }}
$$

It is assumed that there is uniform heat generation within the foil and that the temperature across the thickness of the foil and paint layers are constant as $\mathrm{Bi} \ll 1$ for both the paint and foil layers. This results in the following expression for the convective heat flux due to $\operatorname{EC~}\left(q_{E C}^{\prime \prime}\right)$ :

$$
q_{E C}^{\prime \prime}=q_{g e n}^{\prime \prime}-q_{c o n d}^{\prime \prime}-q_{r a d, b}^{\prime \prime}-q_{l c}^{\prime \prime}-q_{c a p}^{\prime \prime}
$$

where $q_{g e n}^{\prime \prime}$ is the heat flux generated in the foil by Joule heating given by Equation 3. The second term on the RHS accounts for heat lost through conduction across the air gap cavity and is given by Equation 4, where $k_{a g}$ is the thermal conductivity of the bulk fluid (air) and $d T / d z$ is the temperate gradient across the air gap to the IR window. $q_{r a d, b}^{\prime \prime}$ is the total radiative emission from the underside of the foil to the top of the IR transparent $\mathrm{CaF}_{2}$ window and is given by Equation 5. The fourth term in Equation 2 refers to heat transfer due to lateral conduction shown in Equation 6. The partial derivative is solved by means of a central-difference numerical approximation. The final term accounts for the energy stored within the foil between images, also known as the capacitance term, Equation 7.

$$
\begin{gathered}
q_{g e n}^{\prime \prime}=\frac{I_{s} V_{s}}{A_{s}} \\
q_{\text {cond }}^{\prime \prime}=-k_{a g} \frac{d T}{d z} \\
q_{r a d, b}^{\prime \prime}=\frac{\sigma\left(T_{s}^{4}-T_{C a F_{2}}^{4}\right)}{1 / \varepsilon_{p}+1 / \varepsilon_{C a F_{2}}-1} \\
q_{l c}^{\prime \prime}=-\left(k_{f} \delta_{f}+k_{p} \delta_{p}\right)\left(\frac{\partial^{2} T_{s}}{\partial x^{2}}+\frac{\partial^{2} T_{s}}{\partial y^{2}}\right) \\
q_{c a p}^{\prime \prime}=\left(\rho_{f} C_{p, f} \delta_{f}+\rho_{p} C_{p, p} \delta_{p}\right) \frac{\partial T_{s}}{\partial t}
\end{gathered}
$$

\subsubsection{Averaging}

The final stage of processing is to average all images over each test. This assumes that the electrospray cooling is quasi-steady during the 10 second capture period. As will be discussed, this assumption is shown to be valid due to the relatively low calculated energy storage term. The radial profiles are found by taking lines radially outward from the array centre at $60^{\circ}, 0^{\circ}, 300^{\circ}, 240^{\circ}, 180^{\circ}$ and $120^{\circ}$ and averaging. An example of this resultant profile can be seen in Fig. 10.

\section{Uncertainty Analysis}

The experimental uncertainty for all parameters was implemented using the methodology outlined by Kirkup 


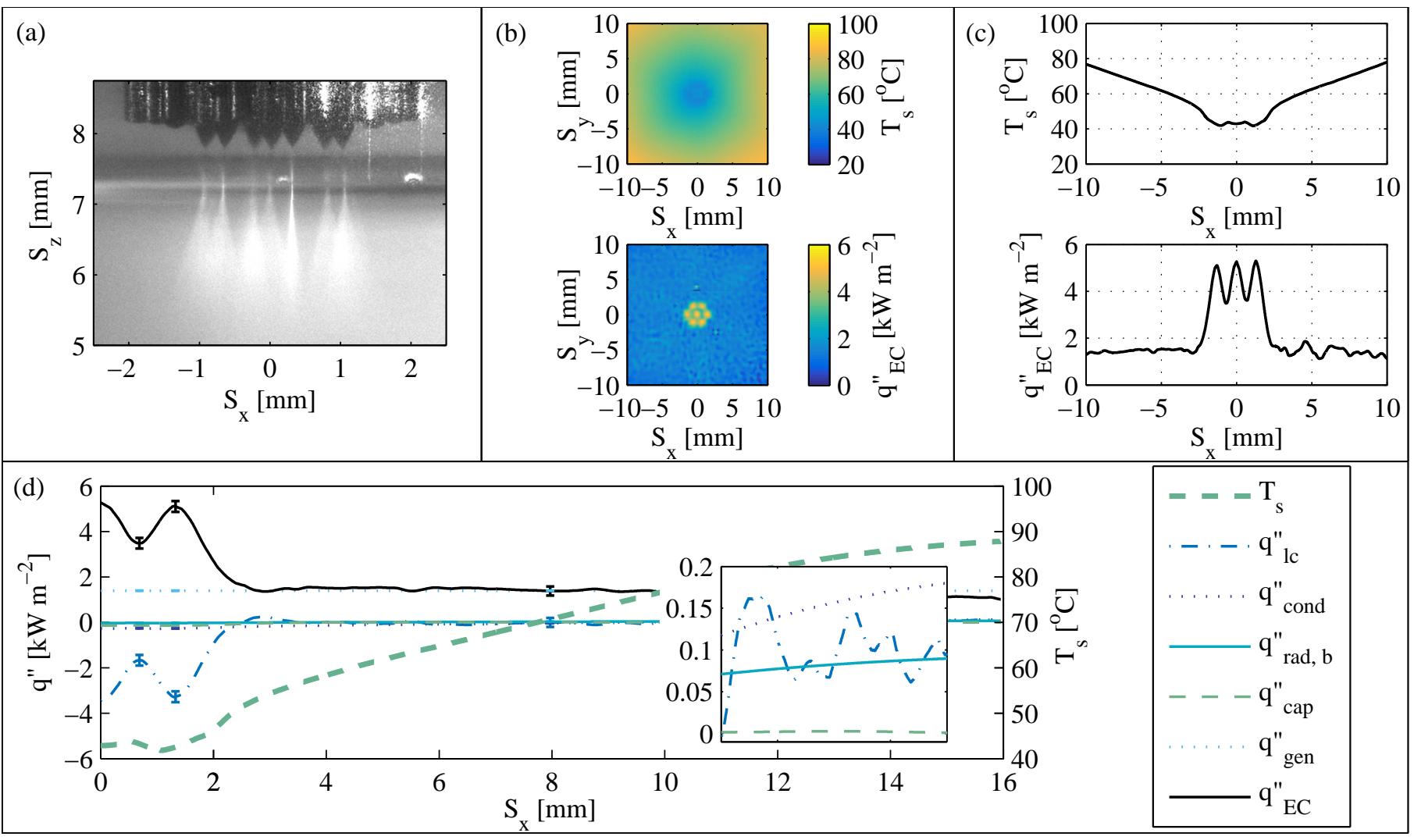

Figure 10: Electrospray array radial evaporative energy component balance. $D_{i}=200 \mu \mathrm{m}, D_{o}=400 \mu \mathrm{m}, H_{1}=0.5 \mathrm{~mm}, H_{2}=7.5 \mathrm{~mm}, Q$ $=3 \mu \mathrm{L} \mathrm{min}{ }^{-1} N_{n}^{-1}, V_{n}=7.1 \mathrm{kV}, V_{e x}=6 \mathrm{kV}, E_{d}=8 \mathrm{kV} \mathrm{cm}^{-1}$, and $q_{g e n}^{\prime \prime}=1,395 \mathrm{~W} \mathrm{~m}^{-2}$.

Table 4: Experimental uncertainty.

\begin{tabular}{lrr}
\hline Parameter & & PU [\%] \\
\hline$T_{s}$ & \pm & 0.25 \\
$T_{\infty}$ & \pm & 0.04 \\
$T_{a g}$ & \pm & 0.04 \\
$Q$ & \pm & $16.6-21.2$ \\
$q_{g e n}^{\prime \prime}$ & \pm & 1.97 \\
\hline
\end{tabular}

and Frenkel [62]. A list of the relevant parameter and their associated percentage uncertainty (PU) are outlined in Table 4. All listed values are to a $95 \%$ confidence level. First the standard uncertainty (SU) of the acquired test data was determined. A combined uncertainty approach was then applied on a pixel by pixel basis to Equation 27. The uncertainty of the foil surface temperature is the experimental standard deviation of the mean. This approach was taken due to the high autocorrelation value attached to sequential $T_{s}$ values. This uncertainty was determined from the calibration curve fit, accounting for the uncertainty attached to the polynomial fit between counts (IR camera data acquisition) and temperature. The expanded uncertainty for the radial profile of $q_{E C}^{\prime \prime}, q_{l_{c}}^{\prime \prime}, q_{c a p}^{\prime \prime}$, $q_{r a d, b}^{\prime \prime}$, and $q_{c o n d}^{\prime \prime}$ are shown graphically in Fig. 10. These values are highlighted at three key points on the radial profile. The $q_{l c}^{\prime \prime}$ term possess the largest attached uncertainty with an expanded uncertainty of $\pm 168.7 \mathrm{~W} \mathrm{~m}^{-2}$ and dom- inates the uncertainty analysis. This results in a typical expanded uncertainty of $\pm 171.2 \mathrm{~W} \mathrm{~m}^{-2}$ for the $q_{E C}^{\prime \prime}$ term.

\section{Results and Discussion}

For an evaporating hydrophilic droplet (Fig. 11), the strong adhesion forces between the liquid and solid phase results in a contact line region of multiple length scales. The disjoining pressure within the adsorbed film region results in a nanometers thick liquid-vapour interface (10$20 \mathrm{~nm}$ ) [64] and prevents evaporation occurring in this region [65]. The transition region is defined by a growing film thickness which results in a reduction in the long range intermolecular forces. This region experiences the highest heat fluxes across the droplet as a result of the low thermal resistance from the small film thickness (1$3 \mu \mathrm{m})[25,64]$. The total length of the adsorbed film and transition region varies from $0.5 \mu \mathrm{m}$ to $10-20 \mu \mathrm{m}$ [64]. As the film thickness increases into the intrinsic meniscus and micro-convection regions, so too does the thermal resistance resulting in a decrease in the local heat flux. Both the intrinsic meniscus and micro-convection regions are characterised by surface tension and inertial forces [63]. This result has been confirmed experimental by Gibbons and Robinson [25] and Karchevsky et al. [64] in their studies on hydrophilic droplet evaporation. 


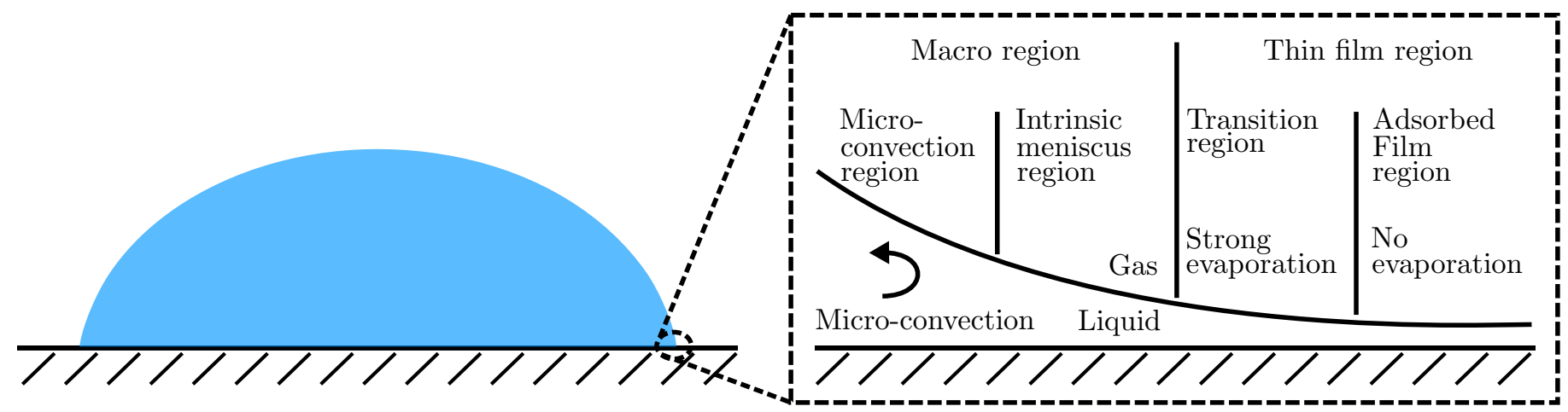

Figure 11: Hydrophilic droplet evaporation at the contact line [63].

Horacek et al. [66] and Sodtke and Stephan [67] both observed a maximum heat flux when the greatest cumulative contact line length density ${ }^{1}$ (CLD), was achieved on their heated substrates during their spray cooling research. As previously shown by Gibbons and Robinson [21] the greatest electrospray cooling is achieved in the evaporative regime of spraying. A potential mechanism to describe this regime can be attributed as the point when numerous droplets, all with their own individual contact lines, are evaporating on the heated substrate. Once the mass flux is increased or $q_{g e n}^{\prime \prime}$ is decreased, an increased coalescence of impinging droplets is noted resulting in a decrease in CLD and subsequent removed heat flux. Due to the spatial resolution of the IR camera, thermal measurements in this study are a local average as they do not have the require fidelity to measure the individual impinging droplet heat transfer.

Following this, the electrospray array was exclusively operated in the evaporative regime for this investigation. An evaporative array cooling case is illustrated in Fig. 10. This test corresponded to $D_{i}=200 \mu \mathrm{m}, D_{o}=400 \mu \mathrm{m}$, $H_{1}=0.5 \mathrm{~mm}, H_{2}=7.5 \mathrm{~mm}, Q=3 \mu \mathrm{L} \min ^{-1} N_{n}^{-1}, V_{n}$ $=7.1 \mathrm{kV}, V_{e x}=6 \mathrm{kV}, E_{d}=8 \mathrm{kV} \mathrm{cm}^{-1}$, and $q_{g e n}^{\prime \prime}=$ $1,395 \mathrm{~W} \mathrm{~m}^{-2}$. Fig. 10a is captured from the optical camera which is focused on the jet forming region and generated spray plume. The plume is illuminated using a low power diode laser $(5 \mathrm{~mW})$ fitted with a $9^{\circ}$ line lens.

The temperature and convective heat flux distributions of the heated foil are shown in Fig. 10b with their corresponding radial profiles shown in Fig. 10c. The final plot, Fig. 10d, shows the individual radial energy balance terms of the array electrospray cooling. A peak convective heat flux of $5,275 \mathrm{~W} \mathrm{~m}^{-2}$ is noted directly below the central array nozzle, at $S_{x}=0 \mathrm{~mm}$, and is notably larger than $q_{g e n}^{\prime \prime}$. This result is in agreement with that observed by Gibbons and Robinson [68] in their single source cone-jet electrospray characterisation. A second peak of $5,111 \mathrm{~W} \mathrm{~m}^{-2}$ is observed at $S_{x}=1.3 \mathrm{~mm}$, and this peak corresponds to the centre of the adjacent nozzles spray plume. The peak is displaced by $0.3 \mathrm{~mm}$ due to repulsion between adjacent

${ }^{1} \mathrm{CLD}=$ contact line length $/$ wetted area spray plumes en-route to the target surface. Both the energy generation term and storage term remain constant at $1,395 \mathrm{~W} \mathrm{~m}^{-2}$ and $8 \mathrm{~W} \mathrm{~m}^{-2}$ respectively as the radial distance from the centre of the array increases. In the case of $q_{g e n}^{\prime \prime}$, this is due to the uniform heat generation within the heated substrate. Local peak lateral conduction values of $q_{l c}^{\prime \prime}=3,448 \mathrm{~W} \mathrm{~m}^{-2}$ and $3,280 \mathrm{~W} \mathrm{~m}^{-2}$ are observed at $S_{x}=0 \mathrm{~mm}$ and $1.3 \mathrm{~mm}$ respectively. These locations correspond to the centre of the central and adjacent spray plumes. They are caused by high thermal gradients in the central region resulting from the high convective heat flux caused by the evaporation of impacting droplets. From $S_{x}=3-16 \mathrm{~mm}$ the convective term $q_{E C}^{\prime \prime}$ decreases steadily from $\approx 1,500-1,010 \mathrm{~W} \mathrm{~m}^{-2}$ as the foil temperature increases. This increasing $T_{s}$ results in increasing values of $q_{\text {cond }}^{\prime \prime}$ and $q_{\text {rad,b }}^{\prime \prime}$. The lateral conduction is low across this region due to the low thermal gradient. The small difference between the $q_{E C}^{\prime \prime}$ and $q_{\text {gen }}^{\prime \prime}$ for $S_{x}=10-16 \mathrm{~mm}\left(\Delta q^{\prime \prime}\right.$ $\left.=280 \mathrm{~W} \mathrm{~m}^{-2}\right)$ is due to the minor yet not negligible $q_{\text {cond }}^{\prime \prime}$ and $q_{\text {rad,b }}^{\prime \prime}$ heat loss terms.

\subsection{Influence of Flow Rate}

Fig. 12 and 13 demonstrates the influence of the working fluid flow rate on the convective heat transfer. Fig. 12 shows the electrospray jet forming region and generated spray plume (left), the convective heat flux distribution (middle) and the radial convective heat flux profile (right) for varied flow rates at a fixed nozzle size, separation height, driving electric field and input heat flux. The radial convective profile consists of lines taken from the centre source at $60^{\circ}, 0^{\circ}, 300^{\circ}, 240^{\circ}, 180^{\circ}$ and $120^{\circ}$. Fig. 12 and 13 show that as the working fluid flow rate is increased so to does the peak, radial profile, and average convective heat flux. This is due to increasing droplet mass flux with increasing flow rate resulting in a greater cumulative CLD on the heated substrate. This result is in agreement with that noted by Gibbons and Robinson [21]. The consistent radial heat flux profiles in shape and magnitude for all flow rates demonstrates the uniform performance across all source nozzles. The average heat flux corresponds to a circular area of $1 \mathrm{~mm}$ diameter around the central nozzle. For reference, the dashed line in Fig. 13a and b denotes the 

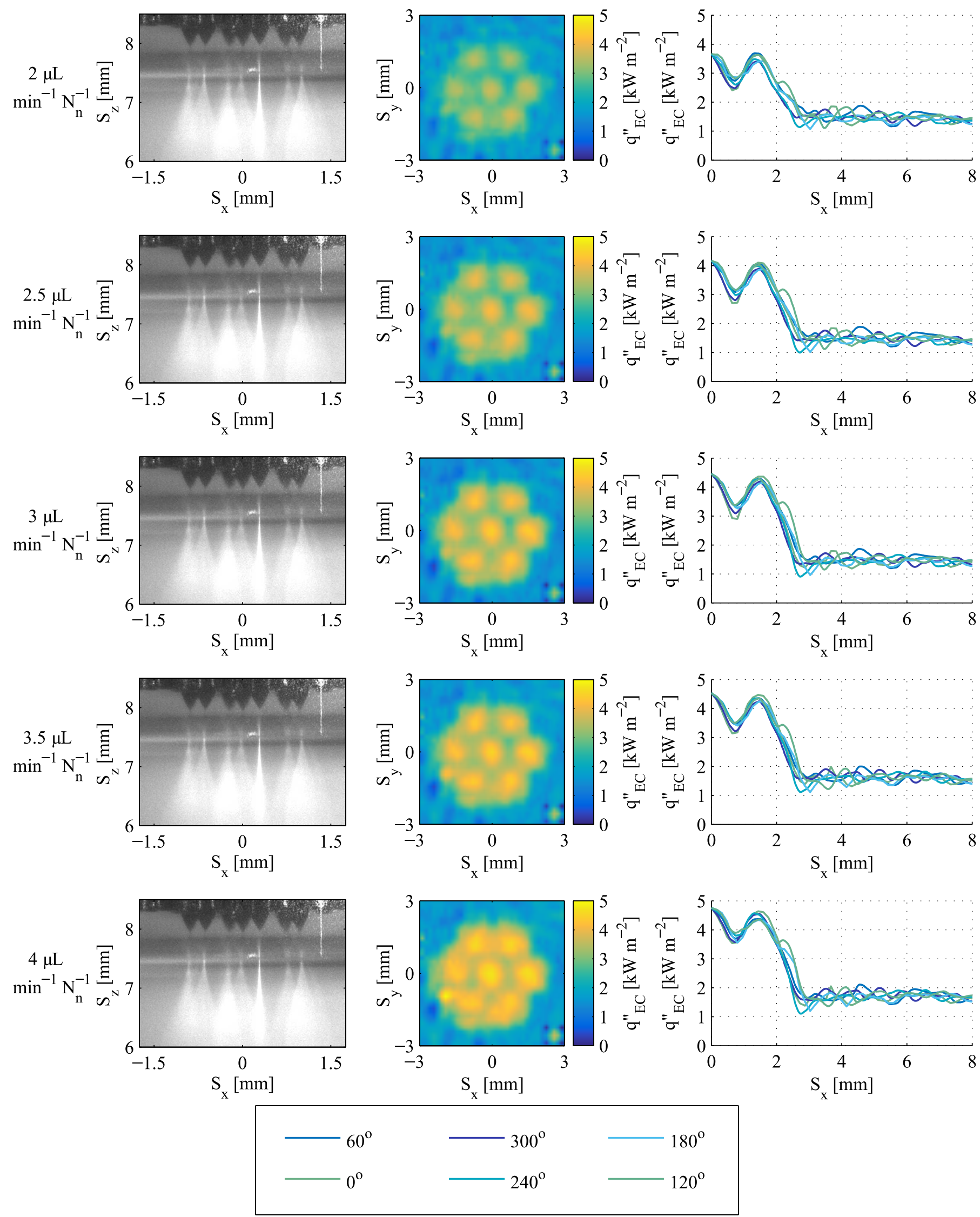

Figure 12: Influence of varied working fluid on plume, heat flux map and radial heat flux profile. $Q=2-4 \mu \mathrm{L}$ min ${ }^{-1} N_{n}^{-1}, D_{i}=200 \mu \mathrm{m}, D_{o}$ $=400 \mu \mathrm{m}, H_{1}=0.5 \mathrm{~mm}, H_{2}=7.5 \mathrm{~mm}, V_{n}=5.55 \mathrm{kV}, V_{\text {ex }}=4.5 \mathrm{kV}, E_{d}=6 \mathrm{kV} \mathrm{cm}^{-1}$, and $q_{g e n}^{\prime \prime}=1,395 \mathrm{Wm} \mathrm{m}^{-2}$. 

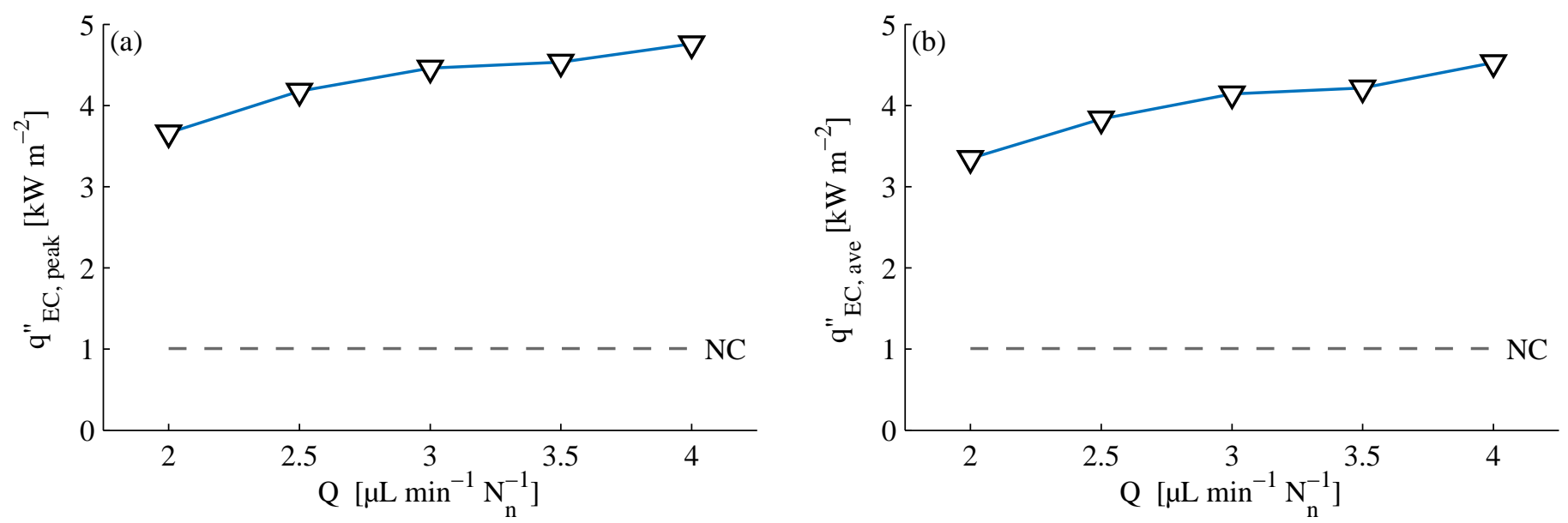

Figure 13: $q_{e c, p e a k}^{\prime \prime}$ and $q_{e c, a v e}^{\prime \prime}$ for varying flow rate. $Q=2-4 \mu \mathrm{L} \mathrm{min}{ }^{-1} N_{n}^{-1}, D_{i}=200 \mu \mathrm{m}, D_{o}=400 \mu \mathrm{m}, H_{1}=0.5 \mathrm{~mm}, H_{2}=7.5 \mathrm{~mm}, V_{n}$ $=5.55 \mathrm{kV}, V_{e x}=4.5 \mathrm{kV}, E_{d}=6 \mathrm{kV} \mathrm{cm}^{-1}$, and $q_{g e n}^{\prime \prime}=1,395 \mathrm{~W} \mathrm{~m}^{-2}$.
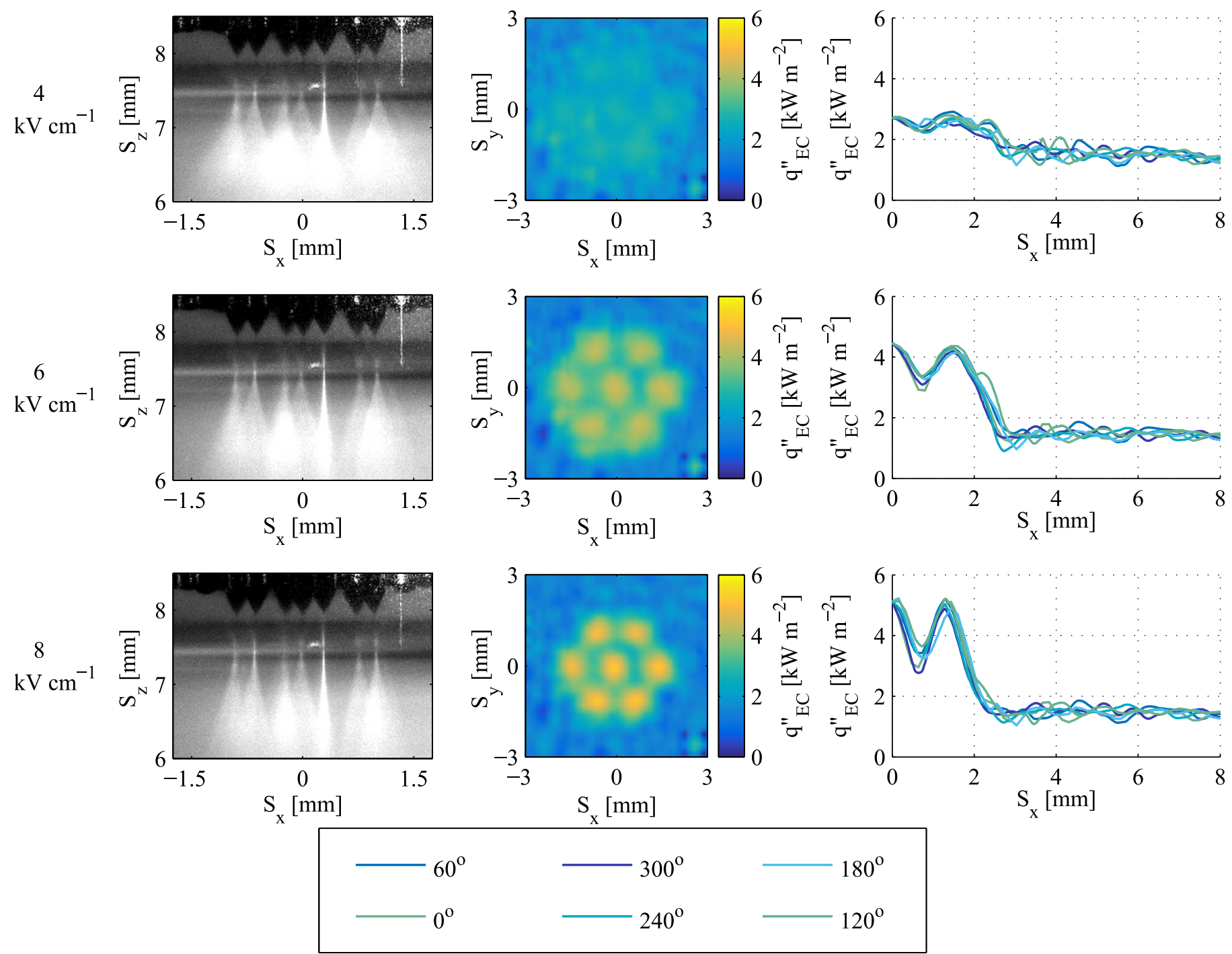

Figure 14: Influence of driving electric field on plume, heat flux map and radial heat flux profile. $E_{d}=4-8 \mathrm{kV} \mathrm{cm}^{-1}, Q=3 \mu \mathrm{L} \mathrm{min}{ }^{-1} N_{n}^{-1}$, $D_{i}=200 \mu \mathrm{m}, D_{o}=400 \mu \mathrm{m}, H_{1}=0.5 \mathrm{~mm}, H_{2}=7.5 \mathrm{~mm}, V_{n}=4.1-7.1 \mathrm{kV}, V_{\text {ex }}=3-6 \mathrm{kV}$, and $q_{g e n}^{\prime \prime}=1,395 \mathrm{Wm}{ }^{-2}$. 

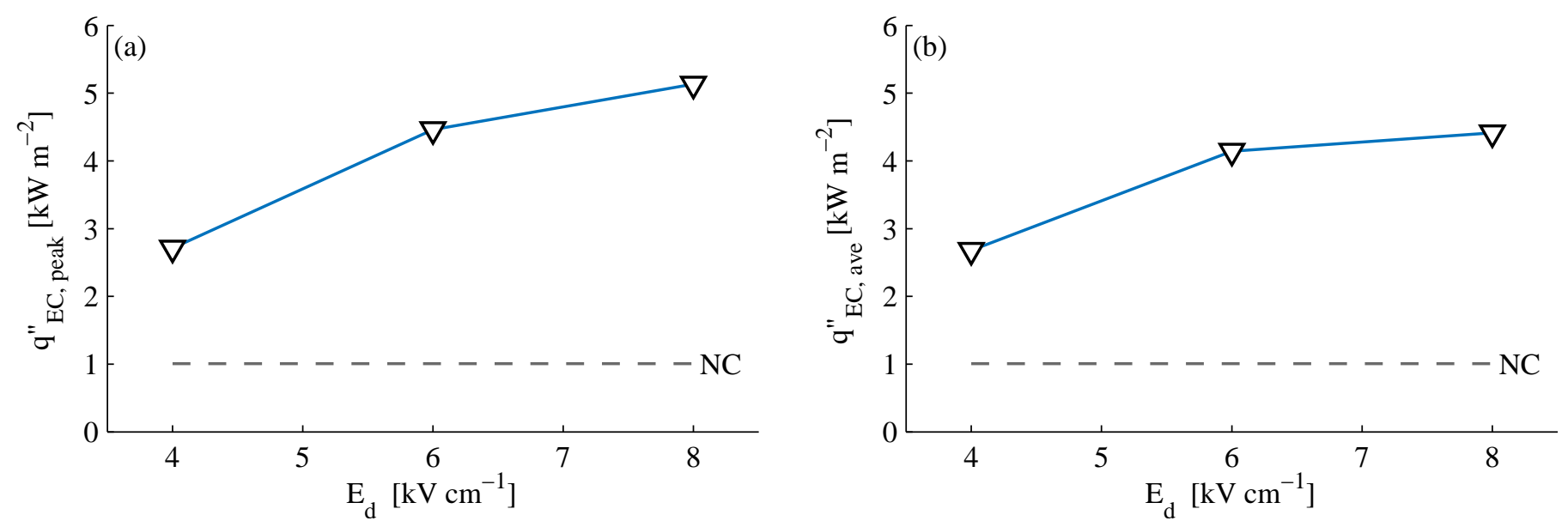

Figure 15: $q_{e c, p e a k}^{\prime \prime}$ and $q_{e c, a v e}^{\prime \prime}$ for varying driving electric field. $E_{d}=4-8 \mathrm{kV} \mathrm{cm}^{-1}, Q=3 \mu \mathrm{L} \mathrm{min}^{-1} N_{n}^{-1}, D_{i}=200 \mu \mathrm{m}, D_{o}=400 \mu \mathrm{m}, H_{1}$ $=0.5 \mathrm{~mm}, H_{2}=7.5 \mathrm{~mm}, V_{n}=4.1-7.1 \mathrm{kV}, V_{e x}=3-6 \mathrm{kV}$, and $q_{g e n}^{\prime \prime}=1,395 \mathrm{~W} \mathrm{~m}^{-2}$.

cooling due to natural convection alone, thus highlighting the notable enhancement that EC has over natural convection.

\subsection{Influence of Driving Electric Field}

Fig. 14 and 15 demonstrates the influence of varied extractor-target electric field strength on the convective heat transfer. From the first column in Fig. 14 it can be qualitatively observed that an increasing driving electric field narrows the individual spray sources. This is due to the increasing downward acceleration of the charged droplets as the electric field strength increases. This reduces the droplet residence time between source and target. As a result the charged droplets have less time over which to repel each other, resulting in a more concentrated spray plume per source. Figures 14 and 15 show that as the driving electric field is increased a subsequent increase in the peak, radial profile and average heat flux is measured. The more defined radial heat flux profile at higher driving electric fields (Fig. 14 column three) highlights the narrowing spray plume and subsequent increased mass flux around the centre line of each plume. The reduced droplet residence time as a result of the increasing driving electric field also serves to reduce the deleterious effect of droplet evaporation while in transit to the target substrate, and increases the droplet impact velocity with the heated substrate. This increases the mass flux impacting on the tar-
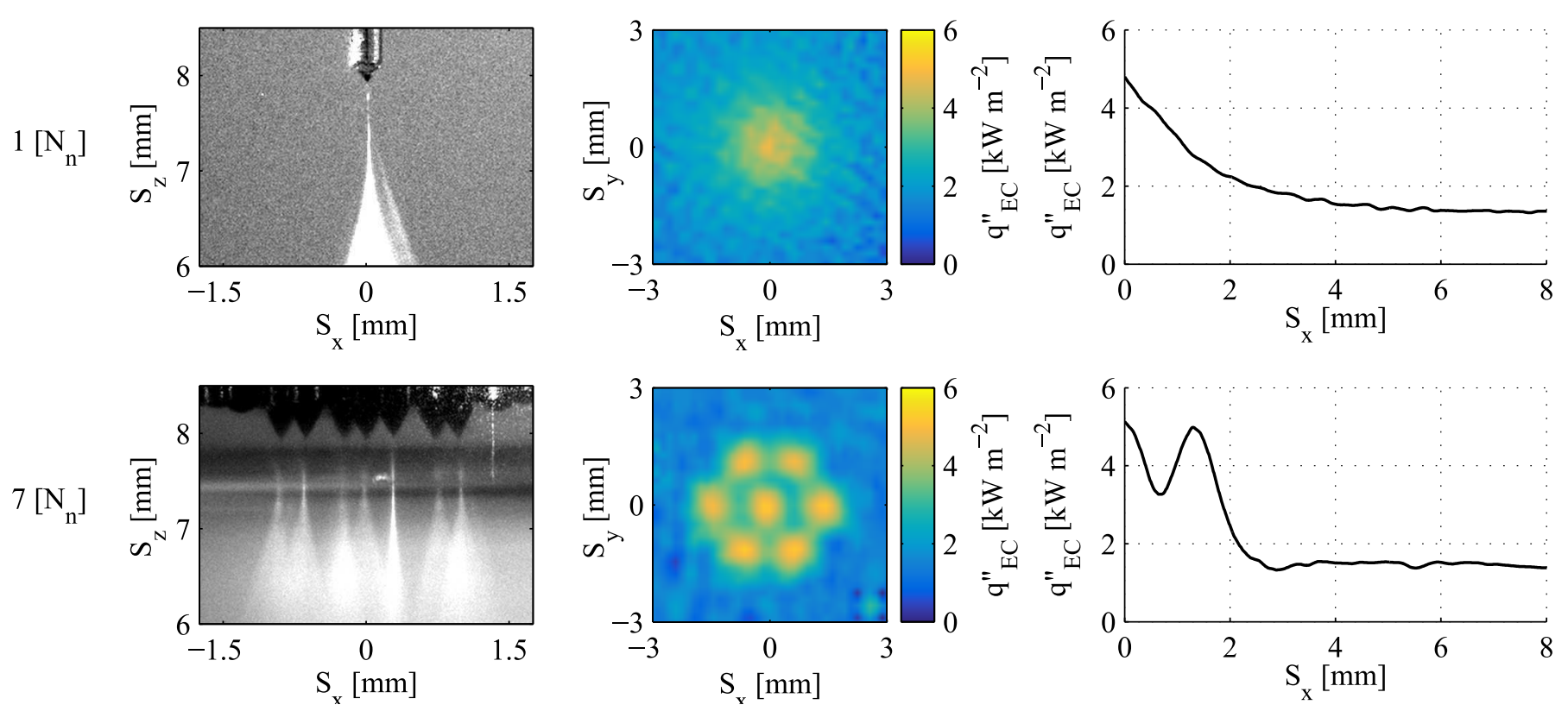

Figure 16: Electrospray comparison. Single source: $V_{n}=2.46 \mathrm{kV}, H=8.2 \mathrm{~mm}, D_{i}=180 \mu \mathrm{m}, D_{o}=321 \mu \mathrm{m}, Q=4 \mu \mathrm{Lmin}{ }^{-1}$, and $q_{g e n}^{\prime \prime}=$ $1,395 \mathrm{~W} \mathrm{~m}^{-2}$. Array: $E_{d}=8 \mathrm{kV} \mathrm{cm}^{-1}, Q=4 \mu \mathrm{L} \mathrm{min}{ }^{-1} N_{n}^{-1}, D_{i}=200 \mu \mathrm{m}, D_{o}=400 \mu \mathrm{m}, H_{1}=0.5 \mathrm{~mm}, H_{2}=7.5 \mathrm{~mm}, V_{n}=5.6 \mathrm{kV}, V_{e x}$ $=4.5 \mathrm{kV}$, and $q_{\text {gen }}^{\prime \prime}=1,395 \mathrm{~W} \mathrm{~m}^{-2}$. 
get surface, which subsequently increases the convective heat flux. The dashed line in Fig. 15a and b denotes cooling due to natural convection alone, again showing the significant enhancement due to electrospray cooling.

\subsection{Single Source - Array Comparison}

Fig. 16 compares an electrospray array cooling with that of a single source under similar operation conditions. Single source: $V_{n}=2.46 \mathrm{kV}, H=8.2 \mathrm{~mm}, D_{i}=180 \mu \mathrm{m}$, $D_{o}=321 \mu \mathrm{m}, Q=4 \mu \mathrm{Lmin}{ }^{-1}$, and $q_{\text {gen }}^{\prime \prime}=1,395 \mathrm{~W} \mathrm{~m}^{-2}$. Array: $V_{n}=7.1 \mathrm{kV}, V_{e x}=6 \mathrm{kV}, E_{d}=6 \mathrm{kV} \mathrm{cm}^{-1}, Q=$ $4 \mu \mathrm{L} \mathrm{min}{ }^{-1} N_{n}^{-1}, D_{i}=200 \mu \mathrm{m}, D_{o}=400 \mu \mathrm{m}, H_{1}=0.5$ $\mathrm{mm}, H_{2}=7.5 \mathrm{~mm}$, and $q_{\text {gen }}^{\prime \prime}=1,395 \mathrm{~W} \mathrm{~m}^{-2}$. The array demonstrates a $7 \%$ increase in the peak heat flux at $S_{x}$ $=0 \mathrm{~mm}$ in comparison to the single source electrospray. This is due to the increased spray plume concentration at $S_{x}=0 \mathrm{~mm}$ due to the applied driving electric field in the three elctrode array configuration. Comparing both systems over a $0.5 \mathrm{~mm}$ radial area from $S_{x}=0 \mathrm{~mm}$, the array and single source achieve a near idential average heat flux over this region. This is reasonable given the similar operating parameters of spraying regime, flow rate, nozzle size, and total separation height. Extending the radial area of comparison to $2 \mathrm{~mm}$ from $S_{x}=0 \mathrm{~mm}$, the array demonstrates a $21 \%$ increase in the average heat flux over this region. This is sensible given the larger coverage area and total working fluid flow rate achieved through the array design, while still sustaining high convective heat flux dissipation in the evaporative regime of spraying. An average wall temperature of $42.6^{\circ} \mathrm{C}$ with a standard deviation of $0.33^{\circ} \mathrm{C}$ is noted for the array. Whereas, for the single source case these values were $57.6^{\circ} \mathrm{C}$ with a standard deviation of $0.62^{\circ} \mathrm{C}$ over the same cooling coverage area.

Delayed onset of pool cooling is observed when contrasting the array and single source electrosprays. Under similar experimental conditions Gibbons and Robinson [21] observed transition from the evaporative to the pool cooling regime at $Q<8 \mu \mathrm{L} \mathrm{min}^{-1}\left(H=7.5 \mathrm{~mm}, D_{i}\right.$ $=0.330 \mathrm{~mm}, D_{o}=0.629 \mathrm{~mm}$, and $\left.q_{\text {gen }}^{\prime \prime}=1,395 \mathrm{~W} \mathrm{~m}^{-2}\right)$. Whereas, the array continues to preform in the evaporative regime at a total flow rate value of $28 \mu \mathrm{L} \mathrm{min}{ }^{-1}$ $\left(4 \mu \mathrm{L} \min ^{-1} N_{n}^{-1}\right)$. This is due to the reduced localisation of the impinging spray mass flux.

\section{Conclusion}

The convective heat transfer to an electrospray array operating in the evaporative regime using thin foil thermography was parametrically investigated. The influence of the working fluid flow rate and driving electric field in this cooling regime was studied. Increasing peak, radial profile, and average convective heat flux was observed for increasing flow rate due to the increasing droplet mass flux as the flow rate is increased. An increase in the peak, radial profile, and average heat flux was also noted for increasing driving electric fields. An $89.2 \%$ and $64.86 \%$ increase in the peak and average heat flux were noted between the lowest and highest applied electric fields. This was due to increasing droplet mass flux, resulting in increasing CLD, from reduced droplet evaporation en-route to the target and narrowing of the spray plume. This narrowing spray plume, at higher driving electric fields, also resulted in a more defined radial heat flux profile. Comparing the arrays performance with that of a single source under similar experimental conditions showed a 1.21 times greater average heat flux and a $26 \%$ lower average wall temperature. This lower wall temperature was noted for a $47 \%$ decrease in the standard deviation of the wall temperature over the compared areas. The results of this work highlight the importance of electrospray arrays in achieving large coverage area uniform cooling and demonstrates the role that the working fluid flow rate and driving electric field play in optimising heat transfer performance.

\section{Acknowledgements}

The authors would like to acknowledge the financial support of the Irish Research Council under Grant No. $\mathrm{RS} / 2012 / 86$.

\section{References}

[1] International Technology Roadmap for Semiconductors, Executive summary, Tech. rep., SIA (2005).

[2] A. Abdoli, G. Jimenez, G. S. Dulikravich, Thermo-fluid analysis of micro pin-fin array cooling configurations for high heat fluxes with a hot spot, International Journal of Thermal Sciences 90 (2015) 290-297.

[3] S. G. Kandlikar, Review and projections of integrated cooling systems for three-dimensional integrated circuits, Journal of Electronic Packaging 136 (2) (2014) 024001.

[4] A. Bar-Cohen, P. Wang, E. Rahim, Thermal management of high heat flux nanoelectronic chips, Microgravity Science and Technology 19 (3-4) (2007) 48-52.

[5] H. F. Hamann, A. Weger, J. A. Lacey, Z. Hu, P. Bose, E. Cohen, J. Wakil, Hotspot-limited microprocessors: Direct temperature and power distribution measurements, Journal of Solid-State Circuits 42 (1) (2007) 56-65.

[6] R. Chen, L. C. Chow, J. E. Navedo, Effects of spray characteristics on critical heat flux in subcooled water spray cooling, International Journal of Heat and Mass Transfer 45 (19) (2002) 4033-4043.

[7] B. Agostini, M. Fabbri, J. E. Park, L. Wojtan, J. R. Thome, B. Michel, State of the art of high heat flux cooling technologies, Heat Transfer Engineering 28 (4) (2007) 258-281.

[8] S. R. Reddy, A. Abdoli, G. S. Dulikravich, C. C. Pacheco, G. Vasquez, R. Jha, M. J. Colaco, H. R. B. Orlande, Multiobjective optimization of micro pin-fin arrays for cooling of high heat flux electronics with a hot spot, in: 13th International Conference on Nanochannels, Microchannels, and Minichannels, ASME, 2015.

[9] A. Jaikumar, S. G. Kandlikar, Enhanced pool boiling for electronics cooling using porous fin tops on open microchannels with fc-87, Applied Thermal Engineering 91 (2015) 426-433.

[10] J. Zeleny, The electrical discharge from liquid points, and a hydrostatic method of measuring the electric intensity at their surfaces, Physical Review 3 (2) (1914) 69.

[11] J. Zeleny, Instability of electrified liquid surfaces, Physical Review 10 (1) (1917) 1. 
[12] M. Cloupeau, B. Prunet-Foch, Electrostatic spraying of liquids: main functioning modes, Journal of Electrostatics 25 (2) (1990) $165-184$.

[13] M. Cloupeau, B. Prunet-Foch, Electrostatic spraying of liquids in cone-jet mode, Journal of Electrostatics 22 (2) (1989) 135159.

[14] W. Deng, Fundamentals and applications of multiplexed electrosprays, Yale University, 2008.

[15] W. Deng, J. F. Klemic, X. Li, M. A. Reed, A. Gomez, Increase of electrospray throughput using multiplexed microfabricated sources for the scalable generation of monodisperse droplets, Journal of Aerosol Science 37 (6) (2006) 696-714.

[16] M. J. Gibbons, Electrospray cooling and droplet evaporation, Ph.D. thesis, Trinity College Dublin, The University of Dublin, Ireland (2017).

[17] W. Deng, A. Gomez, Electrospray cooling for microelectronics, International Journal of Heat and Mass Transfer 54 (11) (2011) 2270-2275.

[18] W. Deng, C. M. Waits, B. Morgan, A. Gomez, Compact multiplexing of monodisperse electrosprays, Journal of Aerosol Science 40 (10) (2009) 907-918.

[19] B. Lojewski, W. Yang, H. Duan, C. Xu, W. Deng, Design, fabrication, and characterization of linear multiplexed electrospray atomizers micro-machined from metal and polymers, Aerosol Science and Technology 47 (2) (2013) 146-152.

[20] R. Bocanegra, D. Galán, M. Márquez, I. G. Loscertales, A. Barrero, Multiple electrosprays emitted from an array of holes, Journal of Aerosol Science 36 (12) (2005) 1387-1399.

[21] M. J. Gibbons, A. J. Robinson, Heat transfer characteristics of single cone-jet electrosprays, International Journal of Heat and Mass Transfer 113 (2017) $70-83$.

[22] G. Taylor, Disintegration of water drops in an electric field, in: Proceedings of the Royal Society of London A: Mathematical, Physical and Engineering Sciences, Vol. 280, The Royal Society, 1964, pp. 383-397.

[23] K. Tang, A. Gomez, On the structure of an electrostatic spray of monodisperse droplets, Physics of Fluids 6 (7) (1994) 23172332 .

[24] W. Deng, A. Gomez, The role of electric charge in microdroplets impacting on conducting surfaces, Physics of Fluids 22 (5) (2010) 051703.

[25] M. J. Gibbons, C. M. Howe, P. Di Marco, A. J. Robinson, Local heat transfer to an evaporating sessile droplet in an electric field, in: Journal of Physics: Conference Series, Vol. 745, IOP Publishing, 2016, p. 032066.

[26] W. Yang, B. Lojewski, Y. Wei, W. Deng, Interactions and deposition patterns of multiplexed electrosprays, Journal of Aerosol Science 46 (2012) 20-33

[27] W. Deng, A. Gomez, Influence of space charge on the scale-up of multiplexed electrosprays, Journal of Aerosol Science 38 (10) (2007) 1062-1078.

[28] M. Yamashita, J. B. Fenn, Electrospray ion source. another variation on the free-jet theme, The Journal of Physical Chemistry 88 (20) (1984) 4451-4459.

[29] B. Q. T. Si, D. Byun, S. Lee, Experimental and theoretical study of a cone-jet for an electrospray microthruster considering the interference effect in an array of nozzles, Journal of Aerosol Science 38 (9) (2007) 924-934.

[30] I. Hayati, A. I. Bailey, T. F. Tadros, Investigations into the mechanisms of electrohydrodynamic spraying of liquids: I. effect of electric field and the environment on pendant drops and factors affecting the formation of stable jets and atomization, Journal of Colloid and Interface Science 117 (1) (1987) 205-221.

[31] G. Lenguito, J. F. de la Mora, A. Gomez, Scaling up the power of an electrospray microthruster, Journal of Micromechanics and Microengineering 24 (5) (2014) 055003.

[32] J. B. Fenn, M. Mann, C. K. Meng, S. F. Wong, C. M. Whitehouse, Electrospray ionization for mass spectrometry of large biomolecules, Science 246 (4926) (1989) 64-71.

[33] O. V. Salata, Tools of nanotechnology: Electrospray, Current Nanoscience 1 (1) (2005) 25-33.
[34] R. L. Hines, Electrostatic atomization and spray painting, Journal of Applied Physics 37 (7) (1966) 2730-2736.

35] A. A. Van Zomeren, E. M. Kelder, J. C. M. Marijnissen, J. Schoonman, The production of thin films of $\mathrm{LiMn}_{2} \mathrm{O}_{4}$ by electrospraying, Journal of Aerosol Science 25 (6) (1994) 12291235 .

[36] J. Doshi, D. H. Reneker, Electrospinning process and applications of electrospun fibers, in: Industry Applications Society Annual Meeting, IEEE, 1993, pp. 1698-1703.

[37] J. M. Grace, J. C. M. Marijnissen, A review of liquid atomization by electrical means, Journal of Aerosol Science 25 (6) (1994) 1005-1019.

[38] M. D. Gabovich, Liquid-metal ion emitters, Physics-Uspekhi 26 (5) (1983) 447-455.

[39] Y. Wu, B. Yu, A. Jackson, W. Zha, L. J. Lee, B. E. Wyslouzil, Coaxial electrohydrodynamic spraying: a novel one-step technique to prepare oligodeoxynucleotide encapsulated lipoplex nanoparticles, Molecular Pharmaceutics 6 (5) (2009) 1371-1379.

40] M. Trotta, R. Cavalli, C. Trotta, R. Bussano, L. Costa, Electrospray technique for solid lipid-based particle production, Drug Development and Industrial Pharmacy 36 (4) (2010) 431-438.

[41] Y. H. Lee, M. Y. Bai, D. R. Chen, Multidrug encapsulation by coaxial tri-capillary electrospray, Colloids and Surfaces B: Biointerfaces 82 (1) (2011) 104-110.

[42] M. J. Maguire, An electrospray solution to the pulmonary delivery problem, Ph.D. thesis, National University of Ireland Maynooth (2010).

[43] G. Chen, A. Gomez, Co-flow laminar diffusion flames of monodisperse sprays: Structure, evaporation and microgravity effects, Combustion Science and Technology 115 (1-3) (1996) $177-201$.

[44] A. Gomez, G. Chen, Charge-induced secondary atomization in diffusion flames of electrostatic sprays, Combustion Science and Technology 96 (1-3) (1994) 47-59.

[45] M. S. Agathou, D. C. Kyritsis, Electrostatic atomization of hydrocarbon fuels and bio-alcohols for engine applications, Energy Conversion and Management 60 (2012) 10-17.

[46] W. Deng, J. F. Klemic, X. Li, M. A. Reed, A. Gomez, Liquid fuel microcombustor using microfabricated multiplexed electrospray sources, Proceedings of the Combustion Institute 31 (2) (2007) 2239-2246.

47] O. Wilhelm, L. Madler, S. E. Pratsinis, Electrospray evaporation and deposition, Journal of Aerosol Science 34 (7) (2003) $815-836$.

[48] J. Fernández De La Mora, J. Navascues, F. Fernandez, J. RosellLlompart, Generation of submicron monodisperse aerosols in electrosprays, Journal of Aerosol Science 21 (1990) 673-676.

[49] D. R. Chen, D. Y. H. Pui, S. L. Kaufman, Electrospraying of conducting liquids for monodisperse aerosol generation in the 4 $\mathrm{nm}$ to $1.8 \mu \mathrm{m}$ diameter range, Journal of Aerosol Science 26 (6) (1995) 963-977.

[50] H. Bostanci, D. Van, B. A. Saarloos, D. P. Rini, L. C. Chow, Spray cooling of power electronics using high temperature coolant and enhanced surface, in: Vehicle Power and Propulsion Conference, IEEE, 2009, pp. 609-613.

[51] R. Zhao, W. Cheng, Q. Liu, H. Fan, Study on heat transfer performance of spray cooling: model and analysis, Heat and Mass Transfer 46 (8-9) (2010) 821-829.

[52] J. Kim, Spray cooling heat transfer: the state of the art, International Journal of Heat and Fluid Flow 28 (4) (2007) 753-767.

[53] G. Liang, I. Mudawar, Review of spray cooling-part 1: Singlephase and nucleate boiling regimes, and critical heat flux, International Journal of Heat and Mass Transfer 115 (2017) 11741205.

[54] G. Liang, I. Mudawar, Review of spray cooling-part 2: High temperature boiling regimes and quenching applications, International Journal of Heat and Mass Transfer 115 (2017) 12061222 .

[55] X. Feng, J. E. Bryan, Application of electrohydrodynamic atomization to two-phase impingement heat transfer, Journal of Heat Transfer 130 (7) (2008) 072202 
[56] H. C. Wang, A. V. Mamishev, Optimal heat transfer performance of the microfluidic electrospray cooling devices, in: 27th Annual Semiconductor Thermal Measurement and Management Symposium, IEEE, 2011, pp. 35-42.

[57] H. C. Wang, A. V. Mamishev, Heat transfer correlation models for electrospray evaporative cooling chambers of different geometry types, Applied Thermal Engineering 40 (2012) 91-101.

[58] I. Golobič, A. E. Bergles, Effects of heater-side factors on the saturated pool boiling critical heat flux, Experimental Thermal and Fluid Science 15 (1) (1997) 43-51.

[59] D. B. Donoghue, A. Albadawi, Y. M. C. Delaure, A. J. Robinson, D. B. Murray, Bubble impingement and the mechanisms of heat transfer, International Journal of Heat and Mass Transfer 71 (2014) 439-450.

[60] O. Raghu, J. Philip, Thermal properties of paint coatings on different backings using a scanning photo acoustic technique, Measurement Science and Technology 17 (11) (2006) 2945.

[61] T. L. Bergman, F. P. Incropera, A. S. Lavine, Fundamentals of heat and mass transfer, Wiley, 2011.

[62] L. Kirkup, R. B. Frenkel, An Introduction to Uncertainty in Measurement: Using the GUM (Guide to the Expression of Uncertainty in Measurement), Cambridge University Press, 2006.

[63] P. A. Raghupathi, S. G. Kandlikar, Contact line region heat transfer mechanisms for an evaporating interface, International Journal of Heat and Mass Transfer 95 (2016) 296-306.

[64] A. L. Karchevsky, I. V. Marchuk, O. A. Kabov, Calculation of the heat flux near the liquid-gas-solid contact line, Applied Mathematical Modelling 40 (2) (2016) 1029-1037.

[65] J. N. Israelachvili, Intermolecular and surface forces, Academic press, 1992.

[66] B. Horacek, K. Kiger, J. Kim, Single nozzle spray cooling heat transfer mechanisms, International Journal of Heat and Mass Transfer 48 (8) (2005) 1425-1438.

[67] C. Sodtke, P. Stephan, Spray cooling on micro structured surfaces, International Journal of Heat and Mass Transfer 50 (19) (2007) 4089-4097.

[68] S. C. Gibson, C. S. Feigerle, K. D. Cook, Fluorometric measurement and modeling of droplet temperature changes in an electrospray plume, Analytical Chemistry 86 (1) (2013) 464472 . 